Archived version from NCDOCKS Institutional Repository http://ibres.uncg.edu/ir/asu/

Whitehead, John C., and Adam Z. Rose. (2009). Estimating Environmental Benefits of Natural Hazard Mitigation with Benefit Transfer: Results from a Benefit-Cost Analysis of FEMA Hazard Mitigation Grants. Mitigation and Adaptation Strategies for Global Change, 14(7):655-676. Publisher's version available from www.springer.com (ISSN: 1381-2386) DOI: 10.1007/s11027-009-9189-2

\title{
Estimating environmental benefits of natural hazard mitigation with data transfer: results from a benefit-cost analysis of Federal Emergency Management Agency hazard mitigation grants
}

John C. Whitehead \& Adam Z. Rose

\begin{abstract}
This paper summarizes methods, data and results associated with the first major attempt to evaluate the environmental benefits of U.S. Federal Emergency Management Agency natural hazards mitigation grants. The study relied heavily on the refinement of benefit transfer methods. Categories of benefits include water quality for recreational and commercial fishing, drinking water, outdoor recreation, hazardous waste, wetlands and aesthetic, health and safety benefits. Environmental and historic benefits proved to be a very minor proportion of the total benefits in dollar terms. Only a very small percentage of earthquake and wind-related hazards yielded environmental benefits, while a sizeable percentage of flood hazard grants did so. We also discuss the prospects that environmental benefits might have been much greater had data been available to analyze more environmental impacts.
\end{abstract}

Keywords Natural hazard . Mitigation . Environmental benefits . Benefit transfer . Earthquake. Flood .Wind . Economics 


\section{Introduction}

The increasing number and severity of both man-made and natural disasters is the subject of growing concern. The impacts of these events are typically measured in terms of property damage, direct and indirect business interruption, injuries, and deaths (Cutter 2001; Cutter and Emrich 2005). Often there is some mention of various categories of other indirect effects, such as sociological and psychological impacts, with some attempts at measurement (Paton 2003; Dash et al. 2007). More recently, awareness of potential environmental impacts has been articulated (Heinz Center 2000), but to this date there has been very little measurement.

The new focus on environmental impacts of natural hazards represents an important paradigm shift. This had previously been ignored in a manner analogous to the philosopher's conundrum - if a tree falls in the forest and there is no one around, is there a noteworthy sound? Likewise, if an earthquake happens in a remote area, is it of any serious interest? In fact, however, resources in remote locations may be needed in the foreseeable future (e.g., trees for lumber or biodiversity for pharmaceuticals) and environmental intrusions emanating from remote areas may have transboundary effects on far flung populated areas (e.g., drifting volcanic ash). This is in addition to the many possible types of environmental damages from hazards that are typically centered in or adjacent to populated areas, including destruction of botanical gardens, salt-water contamination of farmland, fish kills, aesthetic damage, etc. Instances of hazard mitigation for primarily environmental purposes are rare but do exist, a major example being the placement of many miles of the Alaska Oil Pipeline on flexible foundations that reduce the likelihood of breakage, and hence damage to the tundra ecosystem, in the event of an earthquake. Of course, awareness of these impacts is only a first step, and the assessment will only be as successful as the data and methods brought to bear. Damage estimation is even more difficult in this realm, because it relates to "goods and services" that are less tangible than their ordinary counterparts and to situations where market prices do not exist.

The primary objective of this paper is to report on the improvised methods, data, and results associated with the first major attempt to evaluate the environmental benefits of a broad range of natural hazard mitigation activities. The paper summarizes a component of a report to the U.S. Congress on the total benefits of Federal Emergency Management Agency (FEMA) hazard mitigation grants (MMC 2005; Rose et al. 2007). These benefits are in effect the damage prevented by the mitigation activities. We provide a background foundation for and review of benefit transfer methods for estimating environmental benefits of hazard mitigation. Categories of benefits include water quality for recreational and commercial fishing, drinking water, outdoor recreation, hazardous waste, wetlands and aesthetic, health and safety benefits. We first describe the potential environmental benefits of natural hazard mitigation and the stated preference and revealed preference approaches of environmental valuation. We then describe how the benefit estimates were developed for the FEMA study and summarize the benefit estimates used in the benefit-cost analysis. 
Another objective is to place these results in context. The study finds that while environmental benefits of these mitigation projects can be large, they are a very small percentage of total benefits. In other words, other categories of mitigation benefits (e.g., lives saved) dominate. However, the results underestimate impacts for two reasons. First, they omit some types of environmental damages that are very difficult to measure. We identify these impacts and the methods and data that might best be used to measure them in the future, as well as the likely effect their measurement might have on the overall size of the calculations of impacts. Second, there is a bias in the sample because FEMA mitigation grants are oriented toward life and property savings, and environmental benefits would appear to be an afterthought in nearly all cases. Here we identify some areas in which mitigation expressly for environmental objectives is warranted.

The analysis in this paper has broader application to issues relating to other types of impacts that have non-market characteristics, e.g., infrastructure, iconic, and historic sites. Interestingly, mitigation projects expressly intended to protect these values have been implemented for many years, but the ability to measure their benefits lags far behind. We do summarize some results relating to historic sites, and how research in that area can be improved through the lessons learned from our environmental analysis.

Evidence is mounting that both the frequency and severity of floods and wind-related hazards are being increased by climate change (IPCC 2007). Although earthquakes are not affected by environmental change directly, the damage from them is increasing due to human population growth (a continuing aspect of global change) and the persistence of substandard building practices in many parts of the world. Moreover, some of the environmental damages from earthquakes relate to their causing failures of large dams and ensuing flooding. Such cascading hazard events have been dramatized lately by catastrophes such as Hurricane Katrina. Moreover, the damage from hazardous material releases caused by earthquakes, as well as the methodologies for estimating their damage, generalizes from earthquakes to all hazards.

\section{Background}

The Multi-hazard Mitigation Council (MMC) of the National Institute of Building Sciences (NIBS) organized an interdisciplinary research team to quantify the future savings from hazard mitigation activities funded by FEMA grants (MMC 2005; Rose et al. 2007). The study responded to a mandate from Congress and was based on a detailed work plan implemented by a team of experts convened by the MMC Board. Although funding for the study was provided by the FEMA, the study was conducted independently.

Future savings, in terms of losses avoided, were estimated for hazard mitigation activities related to earthquake, wind and flood funded through three major natural hazard mitigation grant programs (the Hazard Mitigation Grant Program, Project Impact, and the Flood Mitigation Assistance Program). Two types of mitigation activity were addressed: "project" and "process" mitigations. Project activities include physical 
measures to avoid or reduce damage from disasters. Process mitigations include activities that lead to policies, practices, and projects that reduce risk and loss.

The MMC study involved two interrelated components. The first estimated the future savings from FEMA mitigation grant expenditures using a statistically representative sample of FEMA-funded mitigation grants so that results could be generalized for the entire population of these grants. The unit of analysis was the individual FEMA-funded grant. The second component assessed the future savings from mitigation activities through empirical research on FEMA-funded mitigation activities carried out in community contexts. The community studies were both quantitative and qualitative and examined mitigation activities in a purposive sample of communities. Both components employed common methodologies, where possible based on benefit-cost analysis. The primary tool used to measure benefits for earthquake and wind hazard mitigation was HAZUS®MH; supplemental methods were used to assess other reduced losses from flood and tornado, business interruption loss for utilities, environmental and historic preservation benefits, and process mitigation activities (MMC 2005).

Not all mitigation measures evaluated in this study could be analyzed using traditional environmental valuation methods. Alternative approaches for assessing some categories of environmental benefits were needed. For environmental and historic benefits, a feasible approach for measuring the benefits of hazard mitigation is the benefit transfer approach. The approach was developed for situations in which the time or money costs of primary data collection are prohibitive. In this approach, benefit estimates from other case studies are spatially or temporally transferred to the policy case study. The overall study found that the benefit cost-ratio (BCR) for nearly six thousand FEMA grants from mid-2003 to mid-2004 was 4-1 (MMC 2005; Rose et al. 2007). Not every grant had a positive BCR, but the study indicates that on average mitigation does pay. Below, we discuss in detail the extent to which environmental benefits contributed to this result.

\section{Environmental Benefits}

Natural hazard mitigation, such as relocation of structures in a floodplain, can lead to environmental benefits such as improved wildlife habitat, improved wetland functions, and increased water quality. Related to these ecological benefits are the increased recreation opportunities and increased property values from open space amenities. Retrofitting and flood proofing of wastewater treatment facilities and other sensitive structures will lead to decreased risk of drinking water contamination and lead to improved human health after hazard events. Earthquake hazard mitigation that reduces the risk of fire and drinking water contamination will increase air quality and drinking water quality, and will thereby lead to improved human health.

A major source of environmental losses from hazard events is the increased debris that must be absorbed by the waste management system and the environment. Some debris are collected and disposed of in landfills and incinerators; others are deposited on land and in the water negatively affecting ecosystems. Existing structural mitigation 
measures address this issue, e.g., structural mitigation measures such as engineering buildings to resist earthquakes and developing designs for hazard resistant construction and retrofitting techniques reduce the damage caused by hurricane winds and flooding. The reduced damages lead to reduced debris removal and disposal. Some of these damages can be minimized by government policy. The extent to which the unmitigated damages should be monetized and considered an economic loss depends on the type of damage, cause and effect, and the context of natural hazard mitigation. For example, consider a pristine wilderness area that experiences a flood event. A large amount of environmental damage would be caused by a flood, including loss of flora and fauna. However, from one perspective this damage is the natural course of nature, and it is inappropriate to measure the economic losses of the environmental damage. However, when humans benefit from the natural environment these environmental damages may be economic losses. For example, hikers may enjoy the pristine wilderness area, and thus lost or degraded hiking trips may, in fact, be economic damages. Loss of non-use (i.e., passive use) values may also be a consideration.

Natural hazard mitigation projects are not typically able to cope with much environmental damage. It is impossible to mitigate damages to a coastal forest area from a hurricane strike. It is impossible to mitigate damages to visibility and, to some extent, health from a volcanic eruption. On the other hand, mitigation processes that focus on information provision can lead to improved human health through advisories to avoid contaminated areas following hazard events.

Public policy, such as natural hazard mitigation, is designed to improve the human condition. In a market economy, public policy should be used to mitigate the impacts of market failure. Some markets are available to allow economic decision makers to selfprotect against risk. For example, some damages can be insured against through organized markets (i.e., flood insurance), while other damages can be remedied through self- protection after the hazard event (i.e., boiling drinking water). Hazard mitigation can minimize the losses for some types of these damages, but it may not have been attempted or may have little effect on others. For example, losses to commercial fishing and forestry due to naturally occurring events have not been targets of hazard mitigation policies. Lessons are available, however, from the related area of technological accidents, such as oil spills, where double-lined tanker hulls help to reduce the probability of breach and booms serve to contain the oil if it is spilled.

In summary, mitigation policies can be used to avoid damages to the natural environment. The effectiveness of these policies should be compared to a baseline of environmental damages that would occur without these policies. On the other hand, it is feasible that mitigation policies cause negative environmental effects. For example, retrofitting requires economic activity and resource use that could negatively impact the environment. Out of necessity (e.g., data limitations) we have not measured the potential negative impacts. However, these impacts are likely minor. 


\section{Environmental Valuation}

There are several non-market valuation methodologies available to estimate the mitigation benefits (Champ, Boyle and Brown 2003). These methodologies include stated preference and revealed preference approaches. The travel cost method, averting behavior method and the hedonic price method are examples of revealed preference approaches. The contingent valuation, contingent behavior, and conjoint/choice analysis methods are examples of stated preference approaches.

\subsection{Revealed preference approaches}

The travel cost method is a revealed preference method that is most often used to estimate the benefits of outdoor recreation; for example, the improved hunting and fishing opportunities in wetlands and floodplains following structural relocation. The travel cost method recognizes that the major cost of outdoor recreation is the travel and time costs incurred to get to the recreation site. Since individuals reside at varying distances from the recreation site, the variation in distance and the number of trips taken are used to trace out a demand curve. The demand curve is used to derive the benefits of the recreation site. With the appropriate demand shifters (i.e., independent variables such as measures of water quality), the benefits of changes in policy variables can be derived.

The averting behavior method recognizes that individuals seek to protect themselves when faced with environmental risk, such as contaminated drinking water, after earthquakes and floods. Defensive behavior requires expenditures that would not normally be made. For example, the purchase of bottled water or water filters may only be made when faced with the risk of contaminated drinking water. These increased expenditures represent a lower bound on the environmental benefits of hazard mitigation that reduces the risk.

The hedonic price method exploits the relationship between characteristics of land and labor markets, including environmental quality, and housing prices and wages. The hedonic price method has been used to value hurricane mitigation (Simmons et al. 2002), earthquakes (Murdoch et al. 1993) and flood zones (Harrison et al. 2001). For example, relocation of structures from floodplains leads to open space amenities for some property owners. These parcels command higher prices in land markets. Job markets with greater locational amenities are associated with lower wages as the supply of labor is higher relative to other locations. The housing price and wage differentials are measures of the implicit price of locational amenities such as open space. Housing and labor market differentiation can be used to trace out the demand for open space and the measure of environmental benefits.

\subsection{Stated preference approaches}

The contingent valuation method is a stated preference approach that elicits willingness (and ability) to pay statements from survey respondents. The survey method involves 
the construction of a hypothetical market. Respondents are informed about the current problem and the policy designed to mitigate the problem. For example, respondents could be presented with a hazard mitigation program that involves the retrofitting of waste-water treatment plants and reduced drinking water contamination following a hurricane, flood, or earthquake. The state of the environment before and after the policy is described. Other contextual details about the policy are provided such as the policy implementation rule (e.g., majority rule) and the payment vehicle (e.g., increased taxes or utility bills). Finally, a hypothetical question is presented that presents respondents with a choice about improved environmental quality (e.g., safe drinking water) and increased costs versus the status quo. In the hazards literature, the contingent valuation method has been used to estimate flood control values (Hammitt et al. 2001; Shabman and Stephenson 1996).

The contingent behavior approach is similar to the contingent valuation method in that it involves hypothetical questions. In contrast, the questions involve hypothetical behavior instead of hypothetical willingness to pay. For example, respondents can be asked about hypothetical hurricane evacuations (Whitehead 2003), recreation trips in floodplains, hypothetical bottled water purchases after hazard events, or hypothetical home location choice with improved floodplain mapping.

\subsection{Benefit transfer}

It is costly to use the revealed and stated preference valuation methods. First, the travel cost and hedonic pricing method require location-specific data sets. A single study would be feasible in the time allotted, but a number of studies, as required to assess the environmental benefits of several mitigation projects, is not feasible due to time constraints. Second, using a single revealed preference method will exclude large classes of environmental values from the benefits assessment. While the travel cost method focuses on recreation benefits, the hedonic price method focuses on benefits to property owners. Since mitigation projects can have recreation, property value and other environmental benefits, a focus on one valuation method could lead to large errors. Consideration of multiple revealed preference valuation methods is costly. The contingent valuation method requires a mail, telephone, or in-person survey that elicits the willingness to pay for changes in governmental policy that leads to environmental change. In the context of hazard mitigation, the survey would describe mitigation policies that limit environmental damage from natural hazards and determine the value of those policies. The entire CVM survey and reporting process would require a significant amount of time.

The benefit transfer approach was developed for situations in which the time and/or money costs of primary data collection are prohibitive. Environmental benefit estimates from other case studies are spatially and/or temporally transferred to the policy case study. There are three types of benefit transfer: benefit estimate transfer (Boyle and Bergstrom 1992), benefit function transfer (Kirchhoff et al. 1997), and meta-analysis (Smith and Pattanayak 2002). Benefit estimate transfer uses summary measures of the environmental benefit estimates directly. Researchers simply obtain a benefit estimate 
from a similar study conducted elsewhere and use it for the current policy analysis case study. Benefit function transfer uses the statistical model to transfer benefits. Characteristics of the current policy situation or case study (e.g., population demographics, site characteristics) are substituted into the statistical model from the transfer case study to develop benefit estimates that are more suitable for the current policy situation than the directly transferred benefit estimates.

Meta-analysis requires the collection of a large number of studies related to the policy situation. A data set is constructed with measures of the environmental benefits as the dependent variable and characteristics of the individual studies (e.g., water quality) as the independent variables. Regression models are developed which are used to relate the study characteristics to environmental benefits. These regression models are used as benefit function transfer models where the characteristics from the case study are inserted and environmental benefits related to the case study are developed.

The benefit function transfer method is typically the preferred of the three methods given time constraints. The benefit transfer method does not consider differences between case studies. This can potentially lead to errors in benefit estimation. A metaanalysis requires significant resources devoted to literature review and interpretation. In contrast, the benefit function transfer method can be used to quickly transfer benefit estimates from one case study to another and develop those estimates around the particular parameters of the case study of interest.

\section{Methods}

After conduct of a pilot study benefits transfer, we decided that project by project benefit transfer analysis would be too time-consuming for a large number of projects. In order to conduct a large number of benefit transfers efficiently, we developed templates for benefit estimation instead. The following sub-sections summarize the benefit transfer methodology for particular types of environmental and historical benefits provided by hazard mitigation. Sensitivity analysis is used to develop upper- and lower-bound estimates (see Appendix).

Note that we focus primarily on studies in the U.S. because benefit transfer methods require adapting results from as close an analogous situation as possible, i.e., the best data for estimating the damages for one region of the U.S. would be from another region in the U.S. We acknowledge a growing amount of valuable research being done worldwide on environmental damage from hazards (see, e.g., Balluz et al. 2001; Gotoh et al. 2002; Khazai et al. 2006; Lin et al. 2006; Lin et al. 2008). There is also a growing literature in the U.S. on the topic, much of which post-dates our study (see, e.g., Walsh et al. 2006; Reible 2007). At the same time, we emphasize that our methods and insights are generally applicable beyond the U.S. to industrialized and developing countries alike. While background conditions differ, as do types and emphases of mitigation measures, the general categories of environmental damages (air and water quality, sensitive eco-systems, aesthetics, recreation, natural resource preservation, etc.) to avoid are universal. 


\subsection{Drinking water}

Mitigation of flood hazards provide drinking water quality benefits. For example, groundwater and surface water supplies can become contaminated after a flood event. A review of 16 averting behavior and contingent valuation studies of the economic value of safe drinking water finds that the monthly mean value of safe drinking water per household is $\$ 69$ (Whitehead and Van Houtven 1997). Trimming the 3 lowest and 3 highest values to avoid the influence of outliers in a small sample, yields a monthly mean midpoint value of safe drinking water of $\$ 39$. We use the lower value for estimation of drinking water benefits. Since there is some uncertainty about whether drinking water problems would be experienced by all households in the municipality, we assume that there is a $50 \%$ chance that the drinking water supply will remain safe. The total benefits are the product of the length of time that drinking water is contaminated, the monthly household benefit, the percentage of households affected and the population.

\subsection{Water quality: Fishing}

Mitigation of flood hazards provides surface water quality benefits that will improve recreational fishing opportunities. For example, hazard mitigation reduces debris and other water contaminants which damage fish stocks. When site specific studies on water quality benefits are not available we assume that water quality benefits are primarily enjoyed by freshwater recreational anglers in the form of increased catch. The U.S. Fish and Wildlife Service (USFWS) report from the 1991 National Survey estimates the value of an additional bass/trout caught per year (Waddington et al. 1994). We use the 1991 report because the USFWS report from the 2001 National Survey was not yet available and the 1996 National Survey fails to estimate reliable measures of the value of bass fishing for Florida due to data limitations.

The total water quality benefit is equal to the product of the number of anglers affected by the policy and the value of additional catch. To calculate the number of anglers, we adopt two conservative assumptions. We assume that the water quality improvement would allow only one in 10 recreational anglers to catch an additional fish. We also calculate the number of anglers in the population using the percentage of those who fish but do not also hunt in the relevant state. This estimate is obtained from the 2001 USFWS National Survey. The number of anglers affected by the hazard mitigation policy is equal to the product of the percentage of anglers in the relevant state, the $10 \%$ of these anglers assumed to enjoy the water quality improvement, and the relevant population. We assume that the negative recreational impacts of a flood event last for 1 year. The total benefit is the product of the time period of damage, the individual benefit, and the number of anglers affected.

Flood hazards that affect marine waters (e.g., sewage spills in the Gulf of Mexico) are assumed to affect the number of saltwater fishing trips. We estimate the access value of trips using benefit estimate transfer (Haab et al. 2001). The number of marine anglers in inland waters off coastal counties is obtained from the National Marine Fisheries 
Service and county trip allocation data found in Haab et al. (2001). Benefits are equal to the product of value per trip and number of trips affected. Sensitivity analysis is conducted over the number of trips affected and the amount of time fishing is affected. Flood hazards that affect marine waters are also assumed to negatively affect commercial fishery landings and ex-vessel value. Landings and ex-vessel value data are obtained from the National Marine Fisheries Service. Sensitivity analysis is conducted over the percentage of landings affected and the amount of time fishing is affected.

\subsection{Dam reinforcement}

\subsubsection{Water quality: Degradation}

Seismic mitigation (i.e., structural reinforcement against earthquakes) of a major river dam is a special case for which benefit templates did not cover all of the types of benefits. Mitigation of this dam in Southern California provides downstream urban water quality benefits as the risk of flooding-related water quality impacts and debris are reduced. These are not necessarily recreational fishing benefits, since the waterway is a concrete canal. Benefit estimate transfer is used. The benefit estimate is the household annual willingness to pay to remove impairment to all of California's water bodies using the contingent valuation method (Larson and Lew 2001).

The river on which the dam is located represents a small fraction of all of the water bodies in California. One approach to dividing the total willingness to pay into the willingness to pay for avoiding coastal water degradation in the city at the mouth of the river is to apply the percentage of water area in Los Angeles County relative to California to the total willingness to pay. This is potentially an overestimate of the benefits since the river is a fraction of the water resources in the County. A more conservative lower and upper willingness to pay estimate, which we adopt, assumes that $10 \%$ and $25 \%$ of the water resources in Los Angeles County would be impacted. The total benefits are the product of the number of years affected, the percentage of the state affected, the household benefit and the population.

\subsubsection{Outdoor recreation}

The reservoir behind the dam provides outdoor recreation benefits such as boating, fishing and other water-based activities. An earthquake event that damages the dam would reduce these benefits. To value these we use the midpoint of benefit estimate transfer and meta-analysis transfer. The benefit estimate transfer is the average recreation value per person per activity day for wildlife viewing and hiking on the Pacific Coast (Rosenberger and Loomis 2000). The meta-analysis transfer employs Table 2 of Rosenberger and Loomis (2000). Values for state-of-the-art valuation methodology variables are chosen to calibrate the meta-analysis function.

We obtain an estimate of the number of trips to the reservoir as the product of recreation participants and the number of trips per participant. Recreation participation 
estimates are from the 1995 National Survey of Recreation and the Environment (NSRE). We assume one trip for each participant and the reduced visitation is for 2 years. The total benefit is the time period affected, the individual benefit, the percentage of the population that participates in recreation and the number of recreation trips.

\subsection{Hospitals and hazardous waste}

Hospitals generate hazardous waste and natural hazard events can disrupt the proper handling and disposal of it. Mitigation of seismic and wind risk reduces the risk of death from exposure to hospital hazardous wastes. We assume the risk of exposure to hazardous waste from a hospital experiencing a natural hazard is small. The benefit estimate transfer method is used. duVair and Loomis (1992) present estimates of the value of avoiding premature death from hazardous waste (e.g., heavy metals) for $25 \%$, $50 \%$, and $75 \%$ reduction in the risk of death. Based on historical data, we assume that a natural hazard event would lead to a small increase in the average risk of premature death $(.01 \%)$. From a baseline of a $25 \%$ reduction in the risk of premature death we assume that the marginal willingness to pay is equal to the average. Then the willingness to pay for a .01\% reduction in the risk of premature death is extrapolated from the benefit estimates assuming linearity. We assume that the increased risk of death is for 2 years. The total benefit is the product of the time period affected, the household benefit and the population.

\subsection{Wetlands}

Projects that involve the purchase and removal of flooded residences create open space areas and, potentially, functioning wetlands. Open space benefits include urban revitalization, tourism and improved property values, among others. In addition, functioning wetlands provide drinking water quality, recreation, groundwater recharge, wildlife habitat benefits. The environmental benefits of these projects are estimated by applying wetland values to each acre created. We adopt low, medium, and high assumptions for the number of acres of open space/wetlands created (a percentage of an acre for each property purchased). We use a meta-analysis of wetland values (Woodward and Wui 2001). We calibrate Woodward and Wui's Model C for the hazard mitigation application by using the mean values for most all independent variables and adjust the benefits estimate for the number of wetland acres provided by the project. In effect, we are conducting benefit estimate transfer averaged over a number of studies adjusted for wetland acres. We adopt low, medium and high assumptions for the number of years of aggregation.

The present value of annual wetland values is measured with discount rates of $r=2 \%$ and $r=7 \%$. The time horizon for benefits is in perpetuity (i.e., $P V=A V / r$ ). The wetland values are not aggregated across the population since the average population of the wetland studies in the meta-analysis is embedded in Model C. The total benefits accrue after the project is concluded with or without a hazard event. Sensitivity analysis is conducted over the acreage of each property, percentage of property acreage that function as wetlands, and the number of years that property provides wetlands 
functions. The total benefits are the product of the number of acres and the per acre benefit.

\subsection{Aesthetic, health and safety benefits from underground power lines}

Burying power lines provides aesthetic, health and safety benefits. Aesthetic benefits are generated as the power lines do not obstruct views. Health benefits may accrue due to reduced electromagnetic pollution. Safety benefits accrue because natural hazards increase the risk that downed power lines will cause negative human health impacts. Aesthetic and health benefits are similar to wetland benefits, in that they accrue after the project is concluded in perpetuity with or without a hazard event.

We use the benefit estimate transfer method to estimate the benefits of burying power lines. A recent unpublished study conducted for the Palm Beach (FL) County Government asked respondents about their willingness to pay to bury power lines (Palm Beach County 2002). The question posed was: "There are a variety of opinions about overhead power lines. Would you be willing to pay an annual tax assessment for the cost of burying some of the overhead power lines in your area? Would you pay $\$ 50 \mathrm{a}$ year or less, between $\$ 50$ and $\$ 100$ per year, over $\$ 100$ per year, or would you be unwilling to pay for this activity?" Despite the lack of appropriate incentives to respond truthfully to this question, the results are the best information about the willingness to pay for burying power lines since no other study has specifically addressed this issue. Annual aesthetic, health and safety benefits are measured by the product of per household total power line benefit and the household population. Benefits accrue with or without a natural hazard event. Sensitivity analysis is conducted over the portion of households affected by power lines.

\subsection{Cultural and historical resources}

Historically important buildings are threatened by natural hazards. Hazard mitigation can protect these structures and the benefits of historic preservation. Cultural and historical values are estimated with the meta-analysis function found in Noonan (2004). The meta-analysis consists of 65 contingent valuation method studies of historical and cultural resources. To calibrate the model, values for state-of-the-art methodology variables and site variables to best fit the case study are chosen. The total benefits are the product of the household benefit (a one-time payment) and the number of households. Strictly speaking, cultural and historical values are not part of the natural environment. However, because they are similar to many standard environmental values in terms of their intangible character and amenability to estimation methods, they are included here.

\section{Results}

Data were acquired for 5479 approved or completed grants for flood, earthquake and wind risk mitigation activities. The data were stratified by hazard type (flood, earthquake, or wind) and mitigation type (project or process activity). A selection of 357 
mitigation grants was made for examination. Each combination of mitigation type (project or process) and hazard represents one stratum. The sample grants were selected to represent the distribution of mitigation costs; to ensure the inclusion of low, medium, and high-cost mitigation efforts in each stratum; and to minimize the uncertainty in the estimated total benefit. Eventually, 257 grant applications had enough information available to be examined for environmental and historical benefits. The earthquake stratum of grants for project mitigation activities includes grants for both structural activities (e.g., base isolation of public buildings) and nonstructural activities (e.g., retrofit of pendant lighting in schools). The majority of sample grants for the wind grant stratum provided hurricane storm shutters and safe rooms. The majority of the grants in the flood grant stratum were for buyouts of residential structures that had experienced repeated flooding.

We developed decision rules that led to the identification of projects that provide environmental and/or historical benefits. The total number of cases with potential environmental impacts and that had enough information for analysis was determined to be 71 . The criterion for determination of whether the project grants may generate environmental impacts was by assessment of the project type description in the Hazard Mitigation Grant Program proposal. Environmental and historic losses are not applicable if the Project Type Description includes the following: Applied Research and Development in the Building Sciences; Developing, Implementing and Enforcing Codes, Standards, Ordinances and Regulations; Feasibility, Engineering and Design Studies; Miscellaneous; Other Equipment Purchase and Installation; Professional Education (Building Inspectors, Architects, Engineers, Contractors, etc.); Public Awareness and Education (Brochures, Workshops, Videos, etc.); Safe Room (Tornado and Severe Wind Shelter)—Private Structures; Warning Systems (as a Component of a Planned, Adopted, and Exercised Risk Reduction Plan); Elevation of Private StructuresRiverine; Mitigation Plans (various); Missing (Project Title is Project Impact). Each of the Project Titles associated with these Project Type Descriptions were reviewed to ensure whether the project should be excluded. Environmental losses are potentially applicable for the following Project Type Descriptions: Acquisition of Private Real Property (Structures and Land)—Riverine (and Coastal); Dry Flood-proofing Public StructuresRiverine; Flood Control—Berm, Levee, or Dike; Localized Flood Control System to Protect Critical Facility; Other Minor Flood Control; Storm-water Management-Culverts (and Detention/Retention Basins); Utility Protective Measures (Electric, Gas, etc.); Water and Sanitary Sewer System Protective Measures; Wetland Restoration/Creation. Environmental losses are potentially applicable for some Protect Titles within the following Project Type Descriptions: Generators; Non Structural Retrofitting/Rehabilitating Public Structures-Seismic; Other Non-Construction (Regular Project Only); Retrofitting Public Structures-Wind; and Structural Retrofitting/Rehabilitating Private Structures-Seismic. The total number of cases with potential historical impacts is 5 . Project Titles were screened for specific properties mentioned. An internet search was conducted to determine if the property may have historic value. 
Results are presented below for three major categories of hazards: earthquake, wind and flood. Additionally, we divide flood mitigation into general and wetland protection. We also present estimates for historic preservation. Each table presents a column of per unit benefit to the affected population, the size of the affected population and lower, middle and upper estimates of benefits. Development of lower, middle and upper estimates of benefits is described in the Appendix.

Five earthquake projects provide environmental and/or historical benefits (Table 1). One project had recreational fishing, drinking water, wildlife watching, hiking and historic benefits. The middle estimate of benefits is over $\$ 5$ million. One project generated only drinking water benefits. One project generated only hazardous waste benefits. Two projects generated only historical benefits. The highest project benefit, $\$ 15$ million, is for earthquake retrofitting of the City Hall Building of a major U.S. city. Two wind hazard projects provide aesthetic benefits and two provide historical benefits (Table 2). The largest benefit estimate is $\$ 1.4$ million for door and window protection for an historic town hall.

Table 1 Environmental benefits of earthquake hazard mitigation (\$2004)

\begin{tabular}{|c|c|c|c|c|c|c|}
\hline \multirow[t]{2}{*}{ Grant ID number } & \multirow[t]{2}{*}{ Benefit type } & \multirow[t]{2}{*}{ Benefit (B) } & \multirow[t]{2}{*}{ Population } & \multicolumn{3}{|c|}{ Total benefit (TB) } \\
\hline & & & & Lower & Middle & Upper \\
\hline 3904 & Drinking Water & 39 & 59,400 & 11,583 & 231,660 & $1,158,300$ \\
\hline 7063 & Historic & 69 & 8,500 & 146,625 & 293,250 & 439,875 \\
\hline 7085 & Recreational Fishing & 37 & 461,522 & 426,908 & $4,269,079$ & $16,908,899$ \\
\hline 7085 & Drinking Water & 39 & 22,917 & 4,469 & 89,376 & 446,882 \\
\hline 7085 & Watching Wildlife & 18 & 15,813 & 17,790 & 142,317 & 422,765 \\
\hline 7085 & Hiking & 12 & 22,237 & 16,678 & 133,422 & 396,342 \\
\hline 7085 & Historic & 100 & 17,145 & 428,625 & 857,250 & $1,285,875$ \\
\hline 7144 & Hazardous Waste & 0.2 & 34899 & 174 & 1745 & 6911 \\
\hline 7151 & Historic & 91 & 329,700 & $7,500,675$ & $15,001,350$ & $22,502,025$ \\
\hline
\end{tabular}

Table 2 Environmental benefits of wind hazard mitigation (\$2004)

\begin{tabular}{|c|c|c|c|c|c|c|}
\hline \multirow[t]{2}{*}{ Grant ID number } & \multirow[t]{2}{*}{ Benefit type } & \multirow[t]{2}{*}{ Benefit (B) } & \multirow[t]{2}{*}{ Population } & \multicolumn{3}{|c|}{ Total benefit (TB) } \\
\hline & & & & Lower & Middle & Upper \\
\hline 2170 & Historic & 69 & 3,346 & 57,719 & 115,437 & 173,156 \\
\hline 4481 & Power Lines & 24 & 3,906 & 2,346 & 23,456 & 70,367 \\
\hline 4493 & Power Lines & 24 & 108 & 65 & 649 & 1,946 \\
\hline 7594 & Historic & 69 & 39,711 & 685,015 & $1,370,030$ & $2,055,044$ \\
\hline
\end{tabular}


Sixteen flood projects provide environmental and/or historical benefits (Table 3). Six projects provide only recreational fishing benefits, two projects provide recreational fishing and drinking water benefits, one project provides drinking water, marine recreational and commercial fishing benefits and one project provides only drinking water benefits. The largest benefits are over $\$ 1.1$ million for protection of a coastal wastewater treatment facility. Fifty-one flood projects involve removal of structures in floodplains and wetlands creation (Table 4). The number of properties ranges from one to 268 . The wetland values per acre range from $\$ 137$ to $\$ 674$. The mean wetland value per acre is $\$ 1046$. The total wetland value is equal to the product of the wetland value per acre and the number of acres. The total wetland values range from $\$ 674$ to $\$ 40,000$. The mean of the total wetland values is $\$ 9946$.

In Table 5 we list all of the project grants evaluated for environmental and historical benefits and included in the final sample. The mean benefit is $\$ 109,000$. The mean benefit

Table 3 Environmental benefits of flood hazard mitigation (\$2004)

\begin{tabular}{llrrrrr}
\multirow{2}{*}{ Grant ID number } & Benefit type & Benefit (B) & Population & \multicolumn{2}{l}{ Total benefit (TB) } \\
\cline { 5 - 7 } & & & & & & \\
& & & & Lower & Middle & \multicolumn{1}{l}{ Upper } \\
\hline 19 & Recreational Fishing & 10 & 1,446 & 374 & 3,738 & 14,805 \\
19 & Drinking Water & 39 & 5,196 & 405 & 5,066 & 25,331 \\
327 & Recreational Fishing & 2 & 887 & 51 & 508 & 2,011 \\
2101 & Drinking Water & 39 & 5,124 & 400 & 4,996 & 24,980 \\
2101 & Commercial Fishing & 0.05 & 26,239 & 1,312 & 2,624 & 13,120 \\
2101 & Marine Recreational Fishing & 2 & 47,235 & 4,747 & 9,494 & 47,471 \\
2457 & Recreational Fishing & 4 & 360,538 & 36,504 & 365,045 & $1,445,863$ \\
2457 & Drinking Water & 39 & 776,774 & 60,588 & 757,355 & $3,786,773$ \\
2464 & Recreational Fishing & 4 & 360,538 & 36,504 & 365,045 & $1,445,863$ \\
2469 & Recreational Fishing & 4 & 118,978 & 12,046 & 120,465 & 477,135 \\
4841 & Recreational Fishing & 4 & 4,232 & 370 & 3,703 & 14,667 \\
5046 & Recreational Fishing & 4 & 5,505 & 500 & 4,996 & 19,787 \\
5883 & Drinking Water & 39 & 34,772 & 2,712 & 33,902 & 169,512 \\
5911 & Recreational Fishing & 1 & 14,873 & 305 & 3,049 & 12,076 \\
5911 & Drinking Water & 39 & 36,313 & 2,832 & 35,405 & 177,026 \\
7299 & Recreational Fishing & 37 & 4,645 & 4,297 & 42,966 & 170,180
\end{tabular}


Table 4 Environmental benefits of flood hazard mitigation: Wetlands creation (\$2004)

\begin{tabular}{|c|c|c|c|c|c|c|c|}
\hline \multirow[t]{2}{*}{ Grant ID number } & \multirow[t]{2}{*}{ Properties } & \multicolumn{3}{|c|}{ Per Acre (B) } & \multicolumn{3}{|c|}{ Annual (TB) } \\
\hline & & Lower & Middle & Upper & Lower & Middle & Upper \\
\hline 2082 & 4 & 45 & 454 & 1,361 & 181 & 1,814 & 5,443 \\
\hline 2977 & 1 & 67 & 674 & 2,023 & 67 & 674 & 2,023 \\
\hline 3167 & 17 & 30 & 300 & 900 & 510 & 5,098 & 15,294 \\
\hline 3562 & 208 & 15 & 147 & 440 & 3,048 & 30,476 & 91,429 \\
\hline 3567 & 178 & 15 & 153 & 460 & 2,727 & 27,269 & 81,806 \\
\hline 3584 & 77 & 19 & 195 & 584 & 1,499 & 14,991 & 44,972 \\
\hline 3637 & 24 & 27 & 272 & 815 & 652 & 6,521 & 19,564 \\
\hline 3644 & 50 & 22 & 220 & 661 & 1,101 & 11,014 & 33,041 \\
\hline 3863 & 13 & 32 & 324 & 971 & 421 & 4,209 & 12,628 \\
\hline 4063 & 7 & 39 & 387 & 1,160 & 271 & 2,706 & 8,117 \\
\hline 4548 & 6 & 40 & 404 & 1,212 & 242 & 2,424 & 7,271 \\
\hline 4551 & 4 & 45 & 454 & 1,361 & 181 & 1,814 & 5,443 \\
\hline 5494 & 262 & 14 & 137 & 411 & 3,594 & 35,936 & 107,809 \\
\hline 6100 & 120 & 17 & 171 & 514 & 2,058 & 20,578 & 61,734 \\
\hline 723 & 3 & 49 & 493 & 1,478 & 148 & 1,478 & 4,433 \\
\hline 974 & 26 & 27 & 266 & 797 & 690 & 6,905 & 20,715 \\
\hline 975 & 179 & 15 & 153 & 459 & 2,738 & 27,378 & 82,134 \\
\hline 1151 & 1 & 67 & 674 & 2,023 & 67 & 674 & 2,023 \\
\hline 1420 & 1 & 67 & 674 & 2,023 & 67 & 674 & 2,023 \\
\hline 1665 & 61 & 21 & 208 & 624 & 1,269 & 12,694 & 38,081 \\
\hline 2218 & 8 & 37 & 372 & 1,116 & 298 & 2,976 & 8,929 \\
\hline 2769 & 179 & 15 & 153 & 459 & 2,738 & 27,378 & 82,134 \\
\hline 2911 & 258 & 14 & 138 & 413 & 3,554 & 35,544 & 106,631 \\
\hline 2914 & 59 & 21 & 210 & 630 & 1,240 & 12,395 & 37,186 \\
\hline 3419 & 7 & 39 & 387 & 1,160 & 271 & 2,706 & 8,117 \\
\hline 3620 & 234 & 14 & 142 & 425 & 3,315 & 33,150 & 99,451 \\
\hline 3638 & 16 & 31 & 305 & 915 & 488 & 4,882 & 14,646 \\
\hline 3662 & 4 & 45 & 454 & 1,361 & 181 & 1,814 & 5,443 \\
\hline 3689 & 83 & 19 & 191 & 572 & 1,582 & 15,816 & 47,447 \\
\hline 3692 & 2 & 55 & 553 & 1,659 & 111 & 1,106 & 3,318 \\
\hline 3707 & 36 & 24 & 242 & 726 & 871 & 8,711 & 26,133 \\
\hline 3963 & 236 & 14 & 141 & 424 & 3,335 & 33,352 & 100,057 \\
\hline 4001 & 49 & 22 & 222 & 665 & 1,086 & 10,856 & 32,568 \\
\hline 4035 & 29 & 26 & 257 & 772 & 746 & 7,465 & 22,394 \\
\hline 4599 & 15 & 31 & 311 & 932 & 466 & 4,662 & 13,987 \\
\hline 4626 & 11 & 34 & 340 & 1,019 & 374 & 3,736 & 11,208 \\
\hline 4694 & 51 & 22 & 219 & 657 & 1,117 & 11,170 & 33,511 \\
\hline 4808 & 26 & 27 & 266 & 797 & 690 & 6,905 & 20,715 \\
\hline 5184 & 46 & 23 & 226 & 677 & 1,038 & 10,377 & 31,131 \\
\hline 5633 & 1 & 67 & 674 & 2,023 & 67 & 674 & 2,023 \\
\hline 5656 & 1 & 67 & 674 & 2,023 & 67 & 674 & 2,023 \\
\hline 5658 & 2 & 55 & 553 & 1,659 & 111 & 1,106 & 3,318 \\
\hline
\end{tabular}


Table 4 (continued)

\begin{tabular}{|c|c|c|c|c|c|c|c|}
\hline \multirow[t]{2}{*}{ Grant ID number } & \multirow[t]{2}{*}{ Properties } & \multicolumn{3}{|c|}{ Per Acre (B) } & \multicolumn{3}{|c|}{ Annual (TB) } \\
\hline & & Lower & Middle & Upper & Lower & Middle & Upper \\
\hline 5716 & 174 & 15 & 154 & 463 & 2,683 & 26,830 & 80,490 \\
\hline 5815 & 2 & 55 & 553 & 1,659 & 111 & 1,106 & 3,318 \\
\hline 5864 & 20 & 29 & 286 & 859 & 573 & 5,725 & 17,176 \\
\hline 6196 & 1 & 67 & 674 & 2,023 & 67 & 674 & 2,023 \\
\hline 6386 & 1 & 67 & 674 & 2,023 & 67 & 674 & 2,023 \\
\hline 6430 & 2 & 55 & 553 & 1,659 & 111 & 1,106 & 3,318 \\
\hline 6473 & 73 & 20 & 198 & 593 & 1,443 & 14,430 & 43,291 \\
\hline 7620 & 6 & 40 & 404 & 1,212 & 242 & 2,424 & 7,271 \\
\hline 7954 & 3 & 49 & 493 & 1,478 & 148 & 1,478 & 4,433 \\
\hline
\end{tabular}

of the five earthquake grants evaluated for environmental and historical benefits is $\$ 4,203,890$ (Table 6). The mean benefit of the 62 flood grants is $\$ 92,755$. The mean benefit of the 4 wind grants is $\$ 377,393$. The mean benefit of the three earthquake projects in the final sample is nearly $\$ 176$ thousand. The average benefit of the 16 flood projects in the

Table 5 Environmental and historical benefits (\$2004)

\begin{tabular}{|c|c|c|c|c|}
\hline \multirow[t]{2}{*}{ Grant ID number } & \multirow[t]{2}{*}{ Hazard } & \multicolumn{3}{|c|}{ Present value total benefit (TB) } \\
\hline & & Lower & Middle & Upper \\
\hline 19 & Flood & 5,570 & 8,804 & 40,136 \\
\hline 2082 & Flood (Wetlands) & 352 & 16,298 & 121,910 \\
\hline 2170 & Wind & 14,521 & 108,810 & 656,450 \\
\hline 2977 & Flood (Wetlands) & 131 & 6,057 & 45,307 \\
\hline 3167 & Flood (Wetlands) & 990 & 45,794 & 342,537 \\
\hline 3562 & Flood (Wetlands) & 5,917 & 273,757 & $2,047,690$ \\
\hline 3567 & Flood (Wetlands) & 5,294 & 244,944 & $1,832,175$ \\
\hline 3584 & Flood (Wetlands) & 2,911 & 134,655 & $1,007,213$ \\
\hline 3637 & Flood (Wetlands) & 1,266 & 58,579 & 438,165 \\
\hline 3644 & Flood (Wetlands) & 2,138 & 98,931 & 740,000 \\
\hline 3863 & Flood (Wetlands) & 817 & 37,811 & 282,828 \\
\hline 3904 & Earthquake & 11,583 & 231,660 & $1,158,300$ \\
\hline 4063 & Flood (Wetlands) & 525 & 24,303 & 181,789 \\
\hline 4548 & Flood (Wetlands) & 471 & 21,770 & 162,842 \\
\hline 4551 & Flood (Wetlands) & 352 & 16,298 & 121,910 \\
\hline 5494 & Flood (Wetlands) & 6,977 & 322,801 & $2,414,538$ \\
\hline 5911 & Flood & 36,618 & 38,454 & 189,102 \\
\hline 6100 & Flood (Wetlands) & 3,995 & 184,843 & $1,382,619$ \\
\hline 7063 & Earthquake & 146,625 & 293,250 & 439,875 \\
\hline 7144 & Earthquake & 174 & 1,745 & 6,911 \\
\hline
\end{tabular}


Table 6 Summary of environmental and historic benefit estimates by hazard (Present Value) (\$2004)

\begin{tabular}{lrrrr} 
& Projects & \multicolumn{1}{c}{ Low } & Mid & High \\
\hline Full Sample & & & & \\
Earthquake & 5 & $\$ 1,710,705$ & $\$ 4,203,890$ & $\$ 8,713,575$ \\
Flood & 62 & $\$ 4,025$ & $\$ 92,755$ & $\$ 635,675$ \\
Wind & 4 & $\$ 186,286$ & $\$ 377,393$ & $\$ 575,128$ \\
& & & & \\
Final sample & 3 & 52,794 & & \\
Earthquake & 16 & 4,645 & $95,85,029$ \\
Flood & 1 & 14,521 & 108,810 & 709,422 \\
Wind & & & & 656,450
\end{tabular}

final sample is nearly $\$ 96$ thousand. The benefit of the lone wind grant in the final sample is $\$ 109$ thousand.

Rose et al. (2007) find that the total benefits of FEMA-funded mitigation grants between mid-1993 and mid-2003 are four times greater than the cost. These grants are intended to prevent physical damage and economic disruption, avoid hundreds of fatalities and thousands of nonfatal injuries, prevent environmental damage and the loss of historic buildings, and reduce human trauma. Within the limitations of our study, environmental and historic benefits were estimated to be very minor in dollar terms. Three out of 25 earthquake grants sampled provided environmental or historical benefits, including improving water quality, protecting historic buildings, and positive health benefits. The benefit of these three grants accounted for less than $1 \%$ of the total benefits in the earthquake project grant stratum. Sixteen of the 42 flood mitigation grants considered yielded environmental benefits. Fourteen of the environmental benefits pertained to establishing wetlands following the removal of structures, rather than direct environmental benefits of reduced flooding per se. The environmental benefit associated with these 16 grants accounts for less than $1 \%$ of the total benefits. Extrapolating the overall results to the population of all FEMA hazard mitigation grants yields aggregate 10-year benefits of about $\$ 14$ billion. The 10-year environmental and historical benefits of hazard mitigation are therefore about $\$ 140$ million.

\section{Broadening the scope of analysis.}

The methods used here and the cases available due to the limited scope of hazard mitigation grants funded lead to a potential underestimation of the environmental benefits of hazard mitigation. The MMC study avoided estimates of, for example, the value of air quality and biodiversity, because there had been little or no documentation of the effects of unmitigated hazards on these environmental endpoints. Recent hazard events such as Florida wildfires and Hurricane Katrina have highlighted the potential for mitigating these impacts. Revealed preference approaches can be used to estimate the environmental costs of these events, and other studies can be used to estimate the 
potential to mitigate these costs. For example, following Hurricane Katrina much economic research has been conducted assessing the negative environmental impacts (e.g., Posados 2007).

Some generalizations can be made about the relative scope and size of environmental impacts of natural hazards, both in the U.S. and elsewhere. Earthquake and wind hazards are unlikely to cause extensive environmental damage directly, except in the most extreme cases where an earthquake causes the diversion of a river or where wind strength is so great as to fell large stands of trees. Otherwise, the impacts are likely to occur indirectly through impacted structures such as dam, levee, or pipeline breaks in the case of the former, or the release of toxic materials and fires started by downed power lines associated with both types of hazards. Floods are more likely to lead to direct environmental damage by various forms of water contamination (including saltwater intrusion) and by reduced biodiversity. This summary should help provide a guide to cases where environmental damage is likely to be high. This would include highintensity earthquake and wind events or more moderate cases in areas where hazardous materials are manufactured/stored or where large tracts of standing timber exist. It would also include cases of major floods, or cases where more moderate flooding could take place in pristine areas, areas with especially sensitive eco-systems, heavily populated areas, or areas where hazardous materials are manufactured or stored.

Many of these environmental impacts cannot readily be mitigated with the options at hand. Wind damage to standing timber cannot be avoided, though it can be reduced for future forests by land-use changes. Likely earthquake impacts on sensitive eco-systems are almost impossible to predict and hence, with the exception of strengthening dams, are unlikely to be viewed as cost-effective strategies. The most effective strategies, though not necessarily the most cost-effective, in reducing all types of environmental impacts, are those that reduce the probability of the event in the first place. Of course, this is not yet possible in the case of earthquakes or wind events, but it is with respect to flood hazards. Reducing the vulnerability of the built and natural environments to those events that do take place is not possible against all hazards but will involve competition for limited resources between potentially impacted categories.

It should also be noted that mitigation itself can cause environmental damage, which should then be added to the cost side of the ledger. The classic example is a dam intended for flood control, where a new reservoir is created that alters an eco-system or destroys a unique scenic view. Interestingly there are a number of regulations that prohibit various types of environmental damage from hazard mitigation activities, though there are few regulations that require mitigation to protect the environment in the first place. The prime examples are associated with the building of structures in hazard prone areas, such as the Alaska pipeline or factories built near bodies of water, or structures that pose grave dangers when breached no matter what the location, such as nuclear power or chemical plants. 
Note also that mitigation benefits are not absolute or dependent solely on physical characteristics of hazards or the geographic areas they affect. They are also highly dependent on public policy responses. In the FEMA study, benefit categories varied significantly by type of hazard. Avoidance of death and injury was the dominant category for earthquake mitigation grants, because of the strong emphasis on life safety in relation to this hazard. Property damage avoidance was the major category for floods, because life safety can be addressed relatively well by warning and because properties vulnerable to repeated flooding are so easy to identify. Direct and indirect business interruption was a major category in wind-related events because small investments in burying power lines underground can prevent major electricity outages in urban areas. In effect, environmental benefits of hazard mitigation are likely to increase over time with the increased trend of public concern for the environment and with increased experience in mitigation of potential damage in this area.

Much of the past research assessing the environmental impacts of natural hazards employs an ex-post revealed preference approach. In other words, researchers assess damages after a disaster event. Future research could broaden the scope of the benefits of mitigation by considering an ex-ante stated preference approach. For example, the contingent valuation method could be used to address the cost of environmental impacts of natural disasters (Carson and Hanemann 2005). This method requires a mail, telephone, or in-person survey that elicits the willingness to pay for changes in governmental policy that leads to environmental change. In the context of hazard mitigation, the survey would describe mitigation policies that limit environmental damage from natural hazards and determine the value of those policies.

After leading respondents through a number of attitudinal and perception questions related to the mitigation policy, willingness to pay questions are presented. The most incentive-compatible form of contingent valuation is the referendum question in which each respondent is randomly assigned one of several different policy costs in the form of tax increases or other realistic payment vehicles. Respondents are then asked if they would be willing to vote for the mitigation policies that limit environmental damage with a tax increase. Willingness to pay for the mitigation policy can be determined from statistical analysis of these discrete choice responses. Regional valuation models in which willingness to pay is related to demographic, regional and other variables could be developed. This model could be used to transfer willingness to pay estimates to other regions.

\section{Conclusions}

We find that the environmental benefit associated FEMA-funded mitigation grants accounts for less than $1 \%$ of the total benefits. However, the estimation of environmental damages from natural hazards is still in its infancy. Recent assessments of research on natural hazards have laid out a broad set of possible environmental impacts, and suggested sources of data, and appropriate methods (see, e,g., Heinz Center 2000), but this only scratches the surface on the actual work that must be done. There are a number of environmental impacts that were not included in our study. The 
conventional items, such as air pollution, would seem to be innocuous. However, recent events like the World Trade Center attacks and Great Hanshin (Kobe) Earthquake indicate that in some instances local air quality effects may be very serious when toxic materials are present or formed by such actions as combustion. Likewise, other likely rare but still possible outcomes such as radiation leaks, infectious disease releases, and incursions on biodiversity may be monumental. A case by case analysis is needed, rather than the application of any generalization from our study that environmental benefits of natural hazard mitigation are relatively minor.

\section{Acknowledgements}

This research is part of a larger report to the U.S. Congress (MMC 2005). The Multihazard Mitigation Council (MMC) of the National Institute of Building Sciences (NIBS) organized the research team, of which the authors were chief environmental specialist and benefit-cost analysis track leader, respectively. The authors acknowledge the helpful input of other researchers involved in the project, but assume full responsibility for any errors or omissions contained in this paper. The authors also acknowledge helpful comments from two journal referees and participants in a session at the 2006 Southern Economic Association Meetings in Charleston, SC. 


\section{Appendix benefit transfer methods}

The parametric changes used in the sensitivity tests of environmental and historical benefit estimates are presented below. Please note that only a subset of the parameters is involved in the estimation of benefits from nearly all mitigation grants. The following notation is used: $T B=$ total benefit and $B=$ individual/household benefit.

Table 7 Drinking water

\begin{tabular}{lccc} 
Parameter & Lower & Middle & Upper \\
\hline $\mathrm{t}$ (Months-Earthquake) & .25 & 1 & 2 \\
$\mathrm{t}$ (Months-Flood) & .10 & .25 & .50 \\
$\beta$ (\% of households affected) & .02 & .10 & .25 \\
\hline
\end{tabular}

$\mathrm{TB}=\mathrm{t} \times \mathrm{B} \times \beta \times \mathrm{H}$; (Earthquake): Lower $=.005 \times \mathrm{B} \times$ households, Middle $=.10 \times \mathrm{B} \times$ households, Upper $=.50$ x B x households; Flood: Lower $=.002 \times$ B x households, Middle $=.025 \times$ B x households, Upper $=.125 \times \mathrm{B}$ $\mathrm{x}$ households

\section{Table 8 Water quality: Recreational fishing}

\begin{tabular}{lccc} 
Parameter & Lower & Middle & Upper \\
\hline $\mathrm{t}$ (Years) & .25 & 1 & 2 \\
$\delta(\%$ that catches one more fish) & .10 & .25 & .50 \\
\hline
\end{tabular}

$\mathrm{TB}=\mathrm{t} \times \mathrm{B} \times \delta \times$ Anglers; Anglers $=\%$ who participate in fishing (NSFHWAR) $\times$ Population; Lower $=.025 \times \mathrm{B}$ x Anglers; Middle $=.25 \times$ B x Anglers; Upper $=.50 \times$ B x Anglers $+(.50 \times$ B x Anglers $)(1+r)$

Table 9 Outdoor recreation trips

\begin{tabular}{lccc} 
Parameter & Lower & Middle & Upper \\
\hline $\mathrm{t}$ (Years) & .25 & 1 & 2 \\
$\theta$ (\% of participants who take 1 trip) & .25 & .5 & .75 \\
\hline
\end{tabular}

$\mathrm{TB}=\mathrm{t} \times \mathrm{B} \times \theta \times$ Participants; Participants $=\%$ who participate in recreation (NSRE) $\times$ Population; Lower $=.0625 \times$ B x Participants; Middle $=.5 \times$ B x Participants; Upper $=.75 \times$. B x Participants $+(.75 \times$ B $\mathrm{x}$ Participants $) /(1+\mathrm{r})$

\section{Table 10 Hospitals and hazardous waste}

\begin{tabular}{lccc} 
Parameter & Lower & Middle & Upper \\
\hline $\mathrm{t}$ (Years) & .25 & 1 & 2 \\
$\beta$ (\% of households affected) & .25 & .50 & .75 \\
\hline
\end{tabular}

$\mathrm{TB}=\mathrm{t} \times \mathrm{B} \times \beta \times$ households; Lower $=.0625 \mathrm{x} \mathrm{B} \times$ Households; Middle $=.5 \times \mathrm{B} \times$ Households; Upper $=.75 \times \mathrm{B}$ $\mathrm{x}$ Households $+(.75 \times \mathrm{B} \times$ Households $) /(1+\mathrm{r})$ 
Table 11 Cultural and historical resources

\begin{tabular}{llll} 
Parameter & Lower & Middle & Upper \\
\hline$\beta$ (\% of households) & .25 & .50 & .75 \\
\hline
\end{tabular}

$\mathrm{TB}=\mathrm{B}$ (one-time payment) $\mathrm{x} \beta \mathrm{x}$ households; Lower $=.25 \times \mathrm{B} \times$ Households; Middle $=.5 \times \mathrm{B} \times$ Households; Upper $=.75 \times$ B x Households

\section{Table 12 Wetlands}

Parameter

Lower

Middle

Upper

$\rho$ ( $\%$ of acres that function as wetlands)

.10

$\lambda$ (acres for each property)

.5

.5

1

$\mathrm{t}$ (number of years that property provides wetlands functions')

2

10

$\mathrm{TB}=\Sigma_{\mathrm{t}}(\mathrm{B} \times \lambda) /(1.02)^{\mathrm{t}} ; \mathrm{B}=\exp (7.90-(0.286 * \ln (\rho \times \lambda)))$, Lower $=\Sigma_{2}(.025 \times \mathrm{B}) /(1.02)^{2}$ Middle $=\Sigma_{10}(.25 \times$ B) $/(1.02)^{10} ;$ Upper $=\Sigma_{30}(.75 \times \mathrm{B}) /(1.02)^{30}$

Table 13 Aesthetic, health and safety benefits from underground power lines

Parameter

Lower

Middle

Upper

$\beta$ ( $\%$ of households)

.25

.50

.75

TB $=\mathrm{B} \times \beta \times$ households; Lower $=.25 \times$ B $\times$ Households; Middle $=.5 \times$ B $\times$ Households; Upper $=.75 \times \mathrm{B} \times$ Households

Table 14 Marine recreational fishing

Parameter

Lower

Middle

Upper

$\mathrm{t}$ (Months)

.25

$\beta$ (\% of trips affected)

.02

1

2

$\mathrm{TB}=\mathrm{t} \times \mathrm{B} \times \beta \times$ Trips; Lower $=.05 \times \mathrm{B} \times$ Trips; Middle $=.10 \times \mathrm{B} \times$ Trips; Upper $=.50 \times \mathrm{B} \times$ Trips

Table 15 Commercial fishing

\begin{tabular}{lccc} 
Parameter & Lower & Middle & Upper \\
\hline $\mathrm{t}$ (Months) & .25 & 1 & 2 \\
$\beta$ (\% of landings affected) & .02 & .10 & .25 \\
\hline
\end{tabular}

$\mathrm{TB}=\mathrm{t} \times \beta \times$ Landings; Lower $=.05 \times$ Landings; Middle $=.10 \times$ Landings; Upper $=.50 \times$ Landings 


\section{References}

Balluz L, Moll D, Martinez MGD, Colindres JEM, Malilay J (2001) Environmental pesticide exposure in Honduras following Hurricane Mitch. Bull World Health Organ 79:288-295

Boyle KJ, Bergstrom JC (1992) Benefit transfer studies: myths, pragmatism, and idealism. Water Resour Res 28:657-663

Champ PA, Boyle KJ, Brown TC (2003) A Primer on Nonmarket Valuation. Kluwer: Boston

Carson RT, Hanemann WM (2005) Contingent valuation. Chapter 17 in handbook of environmental economics: volume 2 valuing environmental changes, edited by KarlGöran Mäler and Jeffrey R. Vincent, New York North-Holland

Cutter S (2001) American hazardscapes, the regionalization of hazards and disasters. Joseph Henry, Washington, DC

Cutter S, Emrich C (2005) Are natural hazards and disaster losses in the U.S. increasing? American Geophysical Union 86:388-89

Dash N, Morrow BH, Mainster J, Cunningham L (2007) Lasting effects of hurricane Andrew on a workingclass community. Natural Hazards Review 8:13-21

duVair P, Loomis J (1992) Household's valuation of alternative levels of hazardous waste risk reductions: an application of the referendum format contingent valuation method. J Environ Manag 39:143-155

Gotoh T, Nishimura T, Nakata M, Nakaguchi Y, Hiraki K (2002) Air pollution by concrete dust from the great Hanshin earthquake. J Environ Qual 31:718-723

Haab TC, Whitehead JC, McConnell T (2001) The economic value of marine recreational fishing in the Southeast United States: 1997 southeast economic data analysis. NOAA Technical Memorandum NMFS-SEFSC-466

Hammitt JK, Liu JT, Liu JL (2001) Contingent valuation of a Taiwanese wetland. Environ Dev Econ 6:259-268

Harrison DM, Smersh GT, Schwartz AL (2001) Environmental determinants of housing prices: the impact of flood zone status. J Real Estate Res 21:3-20

Heinz Center (2000) The hidden costs of coastal hazards: implications for risk assessment and mitigation. Island Press, Washington, DC 
Intergovernmental Panel on Climate Change (IPCC) (2007) Climate change 2007: synthesis report. IPCC,Geneva

Khazai B, Franco G, Ingram JC, Rumbaitis del Rio C, Dias P, Dissanayake R, Chandratilake R, Kanna SJ (2006) Post-december 2004 tsunami reconstruction in Sri Lanka and its potential impacts on future vulnerability. Earthq Spectra 22:S829-S844

Kirchhoff S, Colby BG, LaFrance JT (1997) Evaluating the performance of benefit transfer: an empirical inquiry. J Environ Econ Manage 33:75-93

Larson DM, Lew DK (2001) Clean water in California: what is it worth? Agricultural and resource economics update, University of California, Davis, 3-6

Lin Y, Chang T, Wu C, Chiang T, Lin SI (2006) Assessing impacts of typhoons and the Chi-Chi earthquake on Chenyulan watershed landscape pattern in Central Taiwan using landscape metrics. Environ Manage 38:108-125

Lin WT, Lin CY, Tsai JS, Huang PH (2008) Eco-environmental changes assessment at the Chiufenershan landslide area caused by catastrophic earthquake in Central Taiwan. Ecol Eng 33:220-232

Multihazard Mitigation Council (MMC) (2005) Natural hazard mitigation saves: independent study to assess the future benefits of hazard mitigation activities, volume 2-study documentation. Prepared for the Federal Emergency Management Agency of the U.S. Department of Homeland Security by the Applied Technology Council under contract to the Multihazard Mitigation Council of the National Institute of Building Sciences, Washington, DC (December)

Murdoch JC, Singh H, Thayer M (1993) The impact of natural hazards on housing values: the Loma Prieta earthquake. Am Real Estate Urban Econ Assoc J 21:167-184

Noonan DS (2004) Contingent valuation and cultural resources: a meta-analytic review of the literature. J Cult Econ 27:159-176

Palm Beach County (2002) Final report—Palm Beach County survey of residents. http://www.co.palmbeach.fl.us/Publnf/News_Room/03-03/03-18-03_Survey.htm

Paton D (2003) Disaster preparedness: a social-cognitive perspective. Disaster Prev Manag 12:210-216

Posados B (2007) Economic assessment of the impacts of hurricane Katrina on coastal Mississippi Marine Resources. Mississippi State University, http://www.msstate.edu/dept/crec/disaster.html, Accessed: August 22, 2007

Reible D (2007) Hurricane Katrina: environmental hazards in the disaster area. Cityscape: A Journal of Policy Development and Research 9:53-68 
Rose A, Porter K, Dash N, Bouabid J, Huyck C, Whitehead J, Shaw D, Eguchi R, Taylor C, McLane T, Tobin LT, Ganderton P, Godschalk D, Kiremidjian A, Tierney K, West C (2007) Benefit-cost analysis of FEMA hazard mitigation grants. Natural Hazards Review 8(4):1-15

Rosenberger RS, Loomis JB (2000) Using meta-analysis for benefit transfer: in-sample convergent validity tests of an outdoor recreation database. Water Resour Res 36:1097-1107

Shabman L, Stephenson K (1996) Searching for the correct benefit estimate: empirical evidence for an alternative perspective. Land Economics 72:433-449

Simmons KM, Kruse JB, Smith DA (2002) Valuing mitigation: real estate market response to hurricane loss reduction measures. South Econ J 68:660-671

Smith VK, Pattanayak SK (2002) Is meta-analysis a Noah's Ark for non-market valuation? Environmental and Resource Economics 22:271-296

Waddington DG, Boyle K, Cooper J (1994) 1991 net economic values for bass and trout fishing, deer hunting and wildlife watching. U.S. Fish and Wildlife Service, Washington DC

Walsh WJ, Reible DD, Haas CN, Pardue JH, Bowers TS (2006) An evaluation of chemical contamination in the aftermath of hurricane Katrina. Environment reporter 37 (November):1-12

Whitehead JC (2003) One million dollars per mile? The opportunity costs of hurricane evacuation. Ocean Coast Manag 46:1069-1083

Whitehead JC, Van Houtven G (1997) Methods for valuing the benefits of the safe water drinking act: review and assessment. East Carolina University Department of Economics Working Paper 9705

Woodward RT, Wui YS (2001) The economic value of wetland services: a metaanalysis. Ecol Econ 37:257-

270 